\title{
ATIVIDADE ANTIMICROBIANA DO MEL DE ABELHAS JATAÍ (Tetragonisca angustula) EM CULTIVO DE MICRORGANISMOS DO CONDUTO AUDITIVO DE CANINOS DOMÉSTICOS (Canis familiaris)
}

\author{
Denise de Mello Bobany, ${ }^{1}$ Mariana de Alcantara Pereira Pimentel, ${ }^{2}$ Roberta Rollemberg Cabral Mar- \\ tins, ${ }^{2}$ Bernardino Alves de Souza Netto ${ }^{2}$ e Marcelo Silva de Tolla ${ }^{2}$ \\ 1. Coordenadora de Estágios da UNIFESO. E-mail: debobany@gmail.com \\ 2. Centro Universitário Serra dos Órgãos, Microbiologia.
}

RESUMO

O objetivo do presente trabalho foi investigar, in vitro, a eficácia do mel de Tetragonisca angustula, sobre os microrganismos encontrados nas inflamações dos condutos auditivos de cães. Coletaram-se, através de $s w a b$ estéril, amostras de secreção auricular de cães diagnosticados com otite clínica. O material foi fixado em lâmina de vidro mediante a realização do esfregaço, corado pelo método de Gram, e submetido à identificação microscópica. Inocularam-se as amostras nos meios de cultura Tryptone Soya Broth, sendo incubados em estufa, com temperatura de $35-37^{\circ} \mathrm{C}$ por um período de 24 horas. Constatado que houve crescimento, semearam-se as amostras placas de Petri com os meios de cultura de Chapman, Levine e Mueller-Hinton, e incubadas em estufa a $35-37^{\circ} \mathrm{C}$ durante 24 horas. Para o antibiograma com o mel, foram adaptados discos de papel de filtro, esterilizados em autoclave e embebidos em mel. Colocaram-se os discos impregnados com mel nas placas contendo o material contaminado e estas foram levadas à estufa a $35-37^{\circ} \mathrm{C}$ de temperatura por um período de 24 horas. Este experimento constatou a formação de halos de inibição no antibiograma com o mel da Tetragonisca angustula, mostrando ser o mel desse gênero de abelhas eficaz no controle de Staphylococcus sp, Bacillus sp. e leveduras.

PALAVRAS-CHAVES: Mel, otite, tratamento.

\section{ANTIMICROBIAL ACTIVITY OF THE HONEY OF JATAÍ BEES (Tetragonisca angustula) IN CULTIVATION OF MICROORGANISMS OF THE HEARING CONDUIT OF DOMESTIC CANINES (Canis familiaris)}

The present work aimed to investigate, in vitro, the efficacy of the honey of Tetragonisca angustula, against the microorganisms found in the auditory canal inflammations of dogs. The samples were collected through a sterile swab of secretion of the auditory canal of dogs with clinical otitis. The material was fixed in glass slide by performing the smear, Gram stained, and submitted to microscopic identification. The samples were inoculated in Tryptone Soya Broth culture media and incubated at $37^{\circ} \mathrm{C}$ for 24 hours. After verifying that there was growth, the samples were cultured in Petri's plates containing Chapman, Levine and Mueller-Hinton, and incubated at $37^{\circ} \mathrm{C}$ for 24 hours. Filter paper discs were adapted, sterilized in autoclave and embedded in honey for the antibiogram. The disks impregnated with honey were placed in Petri's plates containing the contamined material and again incubated at $37^{\circ} \mathrm{C}$ for 24 hours. This experiment verified the formation of inhibition halos in the antibiograma with the honey of the Tetragonisca angustula, showing to be effective in the control of Staphylococcus sp, Bacillus sp and yeasts.

KEYWORDS: Honey, otitis, treatment, Tetragonisca angustula. 


\section{INTRODUÇÃO}

A orelha ou ouvido promove a audição, bem como proporciona o sentido do equilíbrio e, assim como os outros órgãos do cão, está sujeita a alterações patológicas e doenças que, de acordo com o foco inflamatório, são separadas em otite externa, otite média e otite interna (OLIVEIRA et al., 2005).

No Brasil, as otites representam de $8 \%$ a $15 \%$ dos casos atendidos nas clínicas veterinárias, sendo que aproximadamente $76,7 \%$ são de otite externa (OLIVEIRA et al., 2005; LEITE et al., 2008).

Cerca de $30 \%$ das otites externas apresentam infecção mista. Os microrganismos mais encontrados são Staphylococcus sp., Bacillus sp. e Malassezia pachydermatis, que podem ser isolados a partir de meato acústico tanto de cães sadios quanto otopatas. Nesses últimos, a microbiota normal encontra-se alterada (MULLER et al., 1985; AUGUST, 1993; COLE et al., 1998; LILENBAUM et al., 2000; NOBRE et al., 2001; JUNCO \& BARRASA, 2002).

O tratamento inicial da otite externa consiste em controlar ou remover os fatores primários, limpar e secar as orelhas, reduzir a inflamação e debelar infecções bacterianas e/ou micóticas. Para tanto, a identificação correta dos agentes etiológicos e o uso apropriado das terapias tópicas e/ou sistêmicas são fundamentais para a cura (MULLER \& KIRK, 1996; NOXON, 2003; ROSYCHUK \& LUTTEGEN, 2004).

A atual tendência mundial na busca de terapias alternativas no tratamento de doenças comuns vem do interesse em minimizar efeitos colaterais normalmente presentes nas terapias convencionais e da necessidade de recursos acessíveis à população. Particularmente nas sociedades onde há desigualdade social profunda, como no continente latino-americano, é alto o custo da medicina científica, dos exames sofisticados, das intervenções cirúrgicas complexas e dos equipamentos modernos de diagnóstico (AVILA-PIRES, 1995; LUZ, 2005).

O mel de abelhas do gênero Apis possui propriedades medicinais bastante conhecidas, com estudos em seres humanos no tratamento de algumas doenças desde a medicina antiga. Sua ação tópica como antibacteriano e cicatrizante já foi comprovada, sendo uma alternativa de baixo custo financeiro (EFEM, 1988; EFEM et al., 1992; EFEM, 1993; ZUMLA \& LULAT,
1989; MOLAN, 1992; WILLIX et al., 1992; EFEM, 1993; AMENDOLAS et al., 2003; GONÇALVES et al., 2005; MALAVAZZI et al., 2005).

Apesar de não existirem muitos relatos científicos do uso do mel de abelha jataí (Tetragonisca angustula) em apiterapia, o mel das abelhas sem ferrão, segundo CORTOPASSI-LAURINO \& GELLI (1984), é utilizado em terapias populares, principalmente, nas zonas rurais e entre indígenas. Acredita-se que diferentes tipos de mel possuam propriedades curativas específicas, sendo empregados para a cura de um amplo espectro de doenças.

A ação in vitro do mel da abelha Nannotrigona testaceicornis, pertencente à tribo Trigonni, a mesma das abelhas jataí, diante de diferentes microrganismos isolados de focos infecciosos foi constatada por GONÇALVES et al. (2005).

As abelhas jataí (Tetragonisca angustula) são nativas da região do estado do Rio de Janeiro e amplamente difundidas por todo território nacional (SILVEIRA et al., 2002). São facilmente adaptáveis e bastante mansas, podendo ser criadas racionalmente em áreas rurais ou urbanas. Como não apresentam ferrão, seu manejo é facilitado, dispensando o uso de equipamentos de proteção e possibilitando o emprego de mão de obra familiar. Seu mel é composto essencialmente de levulose, uma substância mais doce que a sacarose e, por isso, apesar de a quantidade produzida por colônia ser baixa, é muito apreciado, pois seu sabor é peculiar (LOPES et al., 2005).

Além do valor alimentar, o mel das abelhas jataí, assim como dos outros meliponídeos, também é procurado por suas propriedades medicinais. É considerado um alimento e medicamento dos mais completos e nutritivos (LOPES et al., 2005).

O mel de Tetragonisca angustula é mais líquido do que o mel de gênero Apis e é mais rapidamente absorvido quando passado na pele. Apresenta efeitos imunológico, anti-inflamatório, analgésico, sedativo, expectorante, hipossensibilizador e antibacteriano. Seu efeito contra bactérias gram-positivas e negativas deve-se ao fato de ser uma substância chamada inibina, resultado do acúmulo de peróxido de hidrogênio que é produzido pelo sistema da glicoseoxidase do mel (BREYER, 1983; COOPERNATURAL, 2007).

Este experimento objetivou comprovar a ação antimicrobiana do mel de abelha jataí (Tetragonisca 
angustula) em culturas microbianas de secreções otológicas de cães clinicamente diagnosticados com otite externa.

\section{MATERIAL E MÉTODOS}

O experimento foi realizado com cães acolhidos por uma organização não governamental denominada SOS Animal, localizada no município de Teresópolis, Rio de Janeiro. Coletaram-se as amostras de secreção auricular de dezesseis cães adultos, sem raça definida, de ambos os sexos, diagnosticados com otite externa.

O diagnóstico foi obtido por meio de exame físico dos condutos auditivos, verificando-se a presença de exsudação, sensibilidade dolorosa, eritema, edema, descamação, prurido, inquietação e alterações no posicionamento da cabeça.

A fase laboratorial do experimento foi realizada no laboratório de Microbiologia do Curso de Medicina Veterinária do Centro Universitário Serra dos Órgãos, sediado no município de Teresópolis, RJ, no período de março a maio de 2007.

Coletou-se a secreção auricular através de $s w a b$ estéril. Parte do material foi fixado em lâmina de vidro, através da realização do esfregaço, sendo corado pelo método de Gram, para a identificação preliminar dos microrganismos. Inoculou-se o restante da amostra em tubos de ensaio, previamente identificados, contendo meio de cultura Tryptone Soya Broth (TSB), e incubados em estufa, com temperatura de $35-37^{\circ} \mathrm{C}$ por um período de 24 horas. Após esse período, semeou-se o material dos tubos de ensaio em placas de Petri com os meios de cultura de Chapman (ágar manitol), Levine (ágar eosina azul de metileno-lactose) e Muller-Hilton (ágar-ágar), sendo novamente levados à incubação, em estufa a $35-37^{\circ} \mathrm{C}$ durante 24 horas.

O mel foi coletado no Apiário Serrano, localizado no município de Teresópolis, $\mathrm{RJ}$, sempre às doze horas. Para isso, empregou-se uma seringa de $10 \mathrm{~mL}$ estéril com agulha 30 X 10 também estéril. Imediatamente após a coleta, o material foi encaminhado ao Laboratório, para o procedimento do antibiograma.

Para verificação da ausência de contaminação, semeou-se uma gota de mel em tubo de ensaio contendo o meio de cultura TSB, sendo incubado em estufa por 24 horas a $35-37^{\circ} \mathrm{C}$. Após esse período, não foi constatado crescimento bacteriano.
Para o antibiograma com o mel foram adaptados discos de papel de filtro, recortados em círculos de três tamanhos diferentes $(5 \mathrm{~mm}, 7 \mathrm{~mm}$ e $10 \mathrm{~mm})$, para testar a capacidade de impregnação do mel pelo papel de filtro.

Procedeu-se à esterilização dos discos de papel filtro em autoclave e em seguida pingou-se uma gota de mel sobre cada disco. Após a secagem do mel, os discos foram dispostos nas placas contendo o material contaminado, respeitando-se os limites para o crescimento dos halos de inibição.

O antibiograma para antibióticos convencionais foi realizado seguindo os padrões, com discos próprios para antibiograma de cefalexina (CFE), penicilina (PEN), ofloxacina (OFX), enrofloxacina (ENO), ciprofloxacina (CIP) e ampicilina (AMP) do laboratório Sensifar e executado em placa de Petri contendo meio ágar Muller-Hilton.

Para a escolha dos antibióticos para o antibiograma convencional dessa pesquisa considerou-se o fato de serem os fármacos orais mais utilizados nas otites, conforme referido por ROSYCHUK \& LUTTEGEN, (2004).

As placas foram levadas à estufa a $35-37^{\circ} \mathrm{C}$ de temperatura por um período de 24 horas e, posteriormente, realizou-se a leitura do antibiograma. Para comparação entre os halos de inibição formados pelo antibiograma com mel e com antibióticos comerciais, elegeu-se o disco médio, por apresentar o mesmo diâmetro dos discos-padrões.

Das placas de Petri que foram submetidas ao tratamento com o mel, confeccionaram-se lâminas de vidro coradas pelo método de Gram, para identificação dos microrganismos.

\section{RESULTADOS E DISCUSSÃO}

Nas identificações microbianas preliminares foi constatada infecção mista na secreção auricular dos dezesseis cães, corroborando o que foi relatado por MULLER et al. (1985). Os microrganismos encontrados no presente experimento foram Staphylococcus, sp., Bacillus sp. e leveduras. De acordo com AUGUST (1993), COLE et al. (1998), LILENBAUM et al. (2000), NOBRE et al. (2001) e JUNCO \& BARRASA (2002), são estes microrganismos os mais encontrados nas otites externas de cães. 
O mel de Tetragonisca angustula demonstrou ter alta atividade antimicrobiana sobre Staphylococcus sp. Bacillus sp. e leveduras. Resultado semelhante foi encontrado por GONÇALVES et al. (2005), em estudo da ação do mel de Nannotrigona testaceicornis sobre bacilos e cocos.

No antibiograma com o mel da abelha jataí (Tetragonisca angustula), o disco médio apresentou halo de inibição de $18 \mathrm{~mm}$, incluindo o próprio disco de 0,7 $\mathrm{mm}$, conforme pode ser observado na Figura 1.

Esse resultado, quando comparado ao antibiograma convencional, mostrou atividade antimicrobiana do mel menor que a CFL (cefalexina $-40 \mathrm{~mm}$ ), mais alta que OFX (ofloxacina - $15 \mathrm{~mm}$ ), PEN (penicilina $-10 \mathrm{~mm}$ ) e ENO (enrofloxacina - $10 \mathrm{~mm}$ ) e bem próximo de AMP (ampicilina - $21 \mathrm{~mm}$ ) e CIP (ciprofloxacina $-20 \mathrm{~mm}$ ), resultado que, assim como relatado por GONÇALVES et al. (2005), vem demonstrar o excelente potencial terapêutico do mel de abelhas dessa espécie. Esse dado fortalece a importância de se analisar cientificamente mais produtos naturais oriundos da sabedoria popular, obedecendo a uma tendência mundial atual de buscar terapias alternativas para o tratamento de doenças comuns (AVILA-PIRES, 1995; LUZ, 2005).

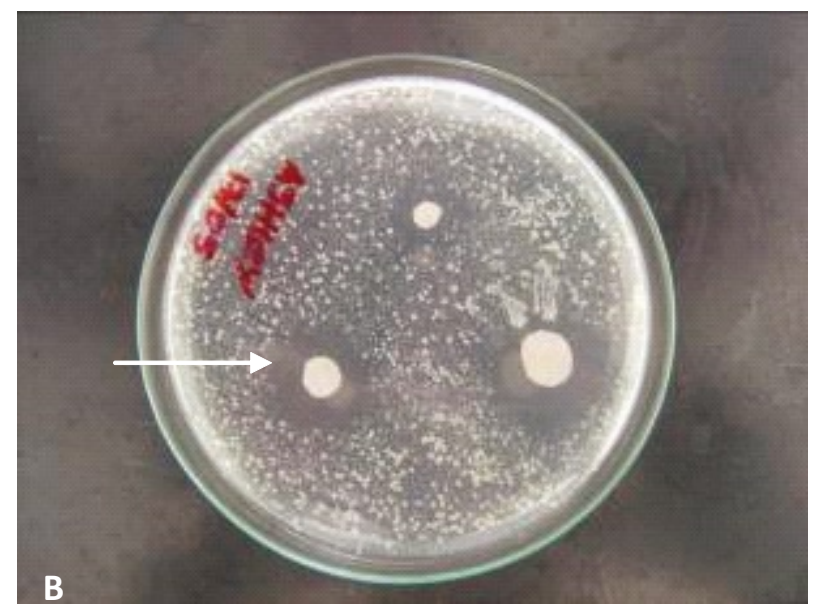

FIGURA 1. A) Halos de inibição formados no antibiograma com antibióticos comerciais. B) Halos de inibição formados no antibiograma com o mel da Tetragonisca angustula.

Para a avaliação, neste estudo, do potencial antimicrobiano do mel de Tetragonisca angustula sobre microrganismos oriundos de secreção do conduto auditivo de cães otopatas, não se realizou o isolamento desses animais. O objetivo era caracterizar a real potencialidade desse material no controle de infecções clínicas, semelhante à metodologia utilizada por GONÇALVES et al. (2005).

$\mathrm{Na}$ amostra de mel semeado em TSB, não houve crescimento microbiano, o que demonstra que a metodologia para coleta de mel de abelha jataí utilizada neste trabalho foi adequada para manter a inocuidade do produto.

No resultado da microbiologia do material colhido das placas de Petri do antibiograma, não foram identificados outros microrganismos além dos preliminarmente encontrados, demonstrando não ter havido interferência de outros elementos patogênicos além dos encontrados nas secreções dos condutos auditivos utilizados no experimento.

\section{CONCLUSÃO}

O mel de abelha jataí (Tetragonisca angustula) mostrou ter nítida ação antimicrobiana em cultivo misto de bacilos, cocos e leveduras, os microrganismos mais encontrados nas otites externas de cães. Portanto, trata-se de produto que pode vir a ser utilizado como alternativa para o tratamento das otopatias de origem microbiana. 


\section{REFERÊNCIAS}

AMENDOLAS, G. F.; ILHA M.; BERGER R.; STEDILE R.; SCHOSSLER J. E. Correção de defeito ósseo femural em cães utilizando implante cortical homólogo conservado em mel. Acta Cirúrgica Brasileira, v. 18, n. 4, 2003.

AUGUST, J. R. Otitis externa: una enfermedad de etiologia multifactorial. Clínica Veterinaria Norte Americana: Práctica Clínica de los Pequeños Animales, v. 18, p. 1-14, 1993.

AVILA-PIRES, F. D. de. Teoria e prática das práticas alternativas. Revista de Saúde Pública, v. 29, n. 2, p. 147-151, 1995.

BREYER, E. U. Abelhas e saúde. 3. ed. Santa Catarina: Uniporto, $1983.80 \mathrm{p}$

COLE L. K.; KWOCHKA, K. W.; KOWALSKI, J. J.; HILLIER, A. Microbial flora and antimicrobial susceptibility patterns of isolated pathogens from the horizontal ear and middle ear dogs with otitis media. Journal of American Veterinary Medical Association, v. 212 , p. $534-538,1998$.

COOPERNATURAL. Abelhas jataí (Tetragonisca angustula). Disponível em: <http://www.coopernatural.com/index.html $>$. Acesso em: 23 maio 2007.

CORTOPASSI-LAURINO, M. E.; GELLI, D. S. Propriedades antibacterianas de méis brasileiros. Ciência e Cultura, v. 36, n. 7, p. 616, 1984.

EFEM, S. E. E. Clinical observations on the wound healing properties of honey. British Journal of Surgery, v. 75, p. 679-681, 1988

EFEM, S. E. E.; UDOCH, K. T.; IWARA, C. I. The antimicrobial spectrum of honey and its clinical significance. Infection, v. 20 , n. 4, p. 227-229, 1992.

EFEM, S. E. E. Recent advances in the management of Fournier's gangrene: preliminary observations. Surgery, v. 113, n. 2, p. $200-$ 204, 1993.

GONÇALVES, A. L.; ALVES FILHO, A.; MENEZES, H. Atividade antimicrobiana do mel da abelha nativa sem ferrão Nannotrigona testaceicornis (Hymenoptera: Apidae, Meliponini). Arquivo Instituto Biológico, v. 72, n. 4, p. 455-459, 2005.

JUNCO, M. T. T.; BARRASA, J. T. M. Identification and antimicrobial susceptibility of coagulase positive Staphylococci isolated from healthy and dogs suffering from otitis externa. Journal of Veterinary Medicine, v. 49, p. 419-423, 2002.

LEITE, F. L.; SÁ, M.; BACH, B. C.; LOVATO, L. T.; LARA, V. M. Staphylococcus sp. isolados de espécimes auriculares de gatos hígidos e sua susceptibilidade antimicrobiana. In: CONGRESSO
BRASILEIRO DE MEDICINA VETERINÁRIA, 35., 2008, Gramado, RS. Anais... Porto Alegre, RS: Sociedade de Veterinária do Rio Grande do Sul. Disponível em: < http://www.sovergs.com. br/conbravet2008/anais/cd/resumos/R0771-1.pdf $>$. Acesso em: 11 fev. 2009.

LILENBAUM, W.; VERAS, M.; BLUM, E.; SOUZA, G. N. Antimicrobial susceptibility of Staphylococci isolated from otitis externa in dogs. Letters in Applied Microbiology, v. 31, p. 42 45, 2000.

LOPES, M.; FERREIRA, J. B.; SANTOS, G. Abelhas sem-ferrão: a biodiversidade invisível. Agriculturas, v. 2, n. 4, 2005. Disponível em: <http://www.aspta.org.br/publique/media/artigo1v2n4.pdf $>$. Acesso em: 24 maio 2006.

LUZ, M. T. Cultura contemporânea e medicinas alternativas: novos paradigmas em saúde no Fim do Século XXI. Revista de Saúde Coletiva, v. 15, p. 145-176, 2005.

MALAVAZZI, G. R.; LAKE, J. C.; DANTAS, P. E. C. Efeito do mel e do soro autólogo na cicatrização do epitélio corneano em coelhos. Arquivo Brasileiro de Oftalmologia, v. 68, n. 3, 2005. Disponível em: $<$ http://www.scielo.br/pdf/abo/v68n3/24737.pdf $>$ Acesso em: 25 maio 2007.

MOLAN, P. C. The antibacterial activity of honey. 1 . The nature of the antibacterial activity. Bee World, v. 73, n. 1, p. 5-28, 1992.

MULLER, G. H.; KIRK, R. W. Dermatologia de pequenos animais. 5. ed. Rio de Janeiro: Interlivros, 1996. 1130 p.

MULLER, G. H.; KIRK, R. W.; SCOTT, D. W. Dermatologia dos pequenos animais. 3. ed. São Paulo: Manole, 1985. 736 p.

NOBRE, M. O.; CASTRO, A. P.; NASCENTE, P. S.; FERREIRO, L.; MEIRELES, M. C. A. Occurrence of Malassezia pachydermatis and others infectious agents as cause external otitis in dogs from Rio Grande do Sul State, Brazil (1996/1997). Brazilian Journal of Microbiology, v. 32, n. 3, p. 245-249, 2001.

NOXON, J. O. Otite externa. In: BICHARD, S.J.; SHERDING, R.G. Manual Saunders: clínica de pequenos animais. 2. ed. São Paulo: Roca, 2003. 1783 p.

OLIVEIRA, L. C.; MEDEIROS, C. M. O.; SILVA, I. N. G.; MONTEIRO, A. J.; LEITE, C. A. L.; CARVALHO, C. B. M. Antimicrobial sensitivity of bacteria from otitis externa in dogs. Arquivo Brasileiro de Medicina Veterinária e Zootecnia, v. 57 , n. 3, p. 405-408, 2005. Disponível em: <http://www.scielo.br/scielo. php?script $=$ sci_arttext\&pid=S0102-09352005000300021\&lng= en\&nrm=iso $>$. Acesso em: 24 maio 2006.

ROSYCHUK, R. A. W.; LUTTEGEN, P. Doenças dos ouvidos In: ETTINGER, S.J.; FELDMAN, E. C. Tratado de Medicina 
Veterinária: doenças do cão e gato. 5. ed. Rio de Janeiro: Guanabara Koogan, 2004. 2256 p.

SILVEIRA, F. A.; MELO, G. A. R.; ALMEIDA, E. A. B. Abelhas brasileiras: sistemática e identificação. Belo Horizonte: Fundação Araucária, 2002. 253 p.
WILLIX, D. J.; MOLAN, P. C.; HARFOOT, C. G. A. Comparison of the sensivity of wound-nfecting species of bacteria activity of manuka honey and other honey. Journal of Applied Bacterology, v. 73, p. 388-394, 1992.

ZUMLA, A.; LULAT, A. Honey: a remedy rediscovered. Journal of the Royal Society of Medicine, v. 82, p. 384-385, 1989.

Protocolado em: 20 ago. 2008. Aceito em: 27 nov. 2009. 